УДК 65.018 .2

DOI $10.21661 / \mathrm{r}-465800$

\title{
E.A. Харитонова
}

\section{КАЧЕСТВО ПРОДУКЦИИ КАК ОБЪЕКТ УПРАВЛЕНИЯ НА ПРЕДПРИЯТИИ}

Аннотация: данная статья направлена на изучение проблемы и роли управления качеством продукиии в производственном процессе. Рассмотрены внешние и внутренние факторы влияния на управление качеством, выявлен первичный объект управления, оказывающий существенное влияние на качество.

Ключевые слова: объект управления, управление качеством, производственная деятельность, внешние факторы влияния, внутренние факторы влияния.

\section{E.A. Kharitonova \\ QUALITY OF PRODUCTS AS AN OBJECT OF MANAGEMENT AT ENTERPRISE}

Abstract: this article is aimed at studying the problem and the role of product quality management in the production process. External and internal factors of influence on quality management are considered, the primary object of management is revealed, which has a significant impact on quality.

Keywords: management object, quality management, production operations, external factors of influence, internal factors of influence.

Как такового, понятия «управление качеством» не существовало еще даже в середине прошлого столетия, но нельзя сказать, что до этого времени качеством не управляли. Конечно же, управляли, редко сознательно, обычно - при возникновении проблем. Поскольку основной целью была борьба с дефектами, то вместо управления качеством использовался контроль, а стандартные функции управления практически не использовались. 
Даже сейчас в большинстве организаций сохраняется подход к управлению качеством, основанный на контроле, но жизнь обязывает преобразовать управление качеством в действительную управленческую деятельность, а не в способ борьбы с дефектами. И этот процесс все больше набирает силу. Так, уже с 50-х годов двадцатого века все больше обращается внимание на то, что качество следует обеспечивать на всех этапах жизненного цикла товара. Джозеф М. Джуран в 1951 г. вводит понятие «спираль качества», где в качестве повторяющихся стадий отмечает:

- исследование рынка;

- разработка проектного задания;

- проектирование;

- составление технических условий;

- разработка технологии и подготовка производства;

- производство;

- контроль качества;

- поставка;

- послепродажное обслуживание;

- утилизация.

А в 60-х годах Арманд В. Фейгенбаум предлагает концепцию всеобщую контроля качества (TQC - Total Quality Control), согласно которой контроль качества должен присутствовать на всех стадиях создания товара. Следующим шагом стало формулирование концепции всеобщего управления на основе качества TQM (Total Quality Management), основные положения которой сводятся к тому, что:

- требуемое качество товара - это то качество, которое нужно потребителю;

- управление качеством необходимо на всех стадиях жизненного цикла товара;

- все участники цепочки производства товара должны участвовать в управлении качеством. 
Цель данной статьи: понять кто, как и каким образом влияет на управление качеством, найти пути решения, чтоб та или иная спроектированная и документированная система качества, включающая управление процессами, заработала.

Актуальность данной статьи заключается в том, что качество - это авторитет фирмы, увеличение прибыли, рост процветания, поэтому работа по управлению качеством фирмы является важнейшим видом деятельности для всего персонала, от руководителя до конкретного исполнителя [3, с. 248]. Качество можно представить в виде пирамиды.

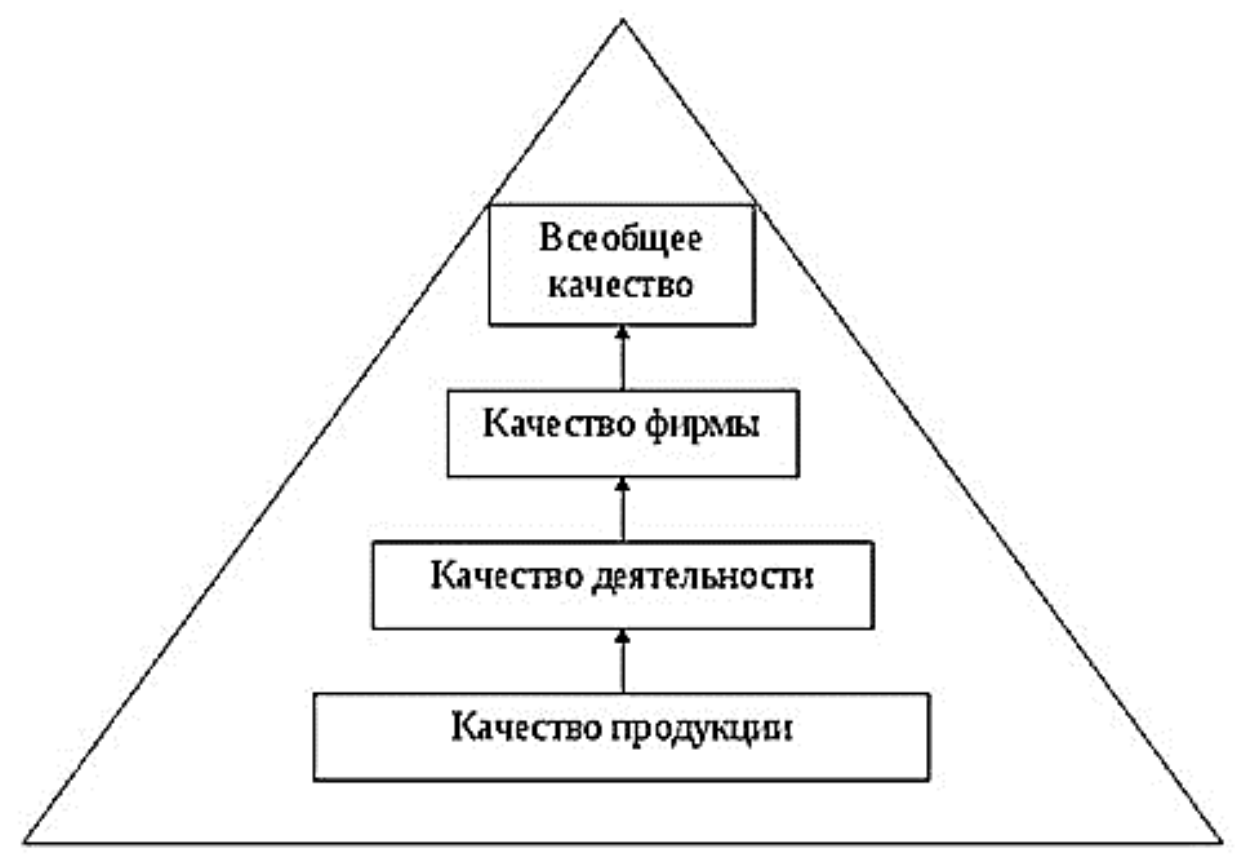

Рис. 1. Пирамида качества

Поэтому, тема «управление качеством» так актуальна на современном этапе развития производства. Ведь во многих странах, в том числе и в России, создана правовая основа управления качеством, которое стало объектом международной стандартизации. Стандарты ISO серии 9000 играют огромнейшую роль в формировании представления об управлении качеством. Развитые страны теперь готовят менеджеров по качеству, а национальные и международные общества по качеству связывают свою деятельность не только с контролем качества, а с качеством в целом. Но не зависимо от всего этого само понятие «управление качеством» до сих пор понимается смутно и неконкретно. Например, в ГОСТ Р ИСО 9000-2008 термин «менеджмент», он же управление, определяется как 
«скоординированная деятельность по руководству и управлению организацией», а термин «менеджмент качества» определяется как «скоординированная деятельность по руководству и управлению организацией применительно к качеству» [1]. Из данных определений можно сделать вывод, что управление качеством это часть управления организацией в целом. А поскольку в стандарте нет информации о том, что подразумевается под «скоординированной деятельностью по руководству и контролю», то далеко не все менеджеры по качеству, да и вообще специалисты, занимающиеся управлением качеством, понимают, чем они управляют, как управляют и что в конечном итоге является объектом при управлении качеством.

Отдельная роль управления качеством заключается в том, что качество - это только один из результатов производственной деятельности, которые являются первыми и важнейшими объектами управления, но вместе с тем оно определяет прямо или косвенно все остальные результаты. Возможность получения нужных результатов, в том числе нужного качества, полностью определяется:

- уровнем требований, предъявляемых к ним;

- процессами, обеспечивающими производственную деятельность;

- персоналом и производственной инфраструктурой, которые необходимы для осуществления процессов;

- ресурсами, которые расходуются при осуществлении процессов;

- финансами, необходимыми для закупок и поддержания в надлежащем состоянии производственной инфраструктуры, обеспечения осуществления процессов, оплаты труда персонала, закупок расходуемых ресурсов и для других нужд производственной деятельности;

- управлением производственной деятельностью [4, с. 22-27].

Это факторы, действующие внутри организации, поэтому их смело можно назвать внутренними факторами влияния.

Состояние остальных факторов определяют такие показатели как требования к результатам, устанавливаемые как цели, задачи, проектные или плановые показатели. Для выполнения данных требований выбираются процессы, 
расходуемые материалы (ресурсы), оборудование, персонал, определяются пути финансирования. На самом деле, при высоких требованиях потребителя к качеству товара, срокам производства и объему, просто необходимо привлекать персонал с более высокой квалификацией, использовать надежное оборудование, качественное сырье, точную измерительную технику и т. п., также потребуются более высокие финансовые затраты на это. Если же потребитель не предъявляет жестких требований к качеству товара, срокам и объемам производства, то можно обойтись более дешевыми процессами, ресурсами, оборудование, уровень квалификации персонала несколько ниже.

Качество и состояние внутренних факторов влияния должно быть объектом управления.

Помимо внутренних факторов на производственную деятельность также влияют такие внешние факторы как социальное давление и установленные законами и нормативными актами требования, которые определенным образом ограничивают производственную деятельность. Организация обязана управлять ответными действиями на влияние данных факторов, чтобы завоевать лояльное отношение общества и обеспечить выполнение законов, минимизируя при этом затраты на данные мероприятия, поскольку управлять данными факторами она не может.

Схема объектов управления в производственной деятельности представлена на рисунке 1 [4, с. 22-27]. 


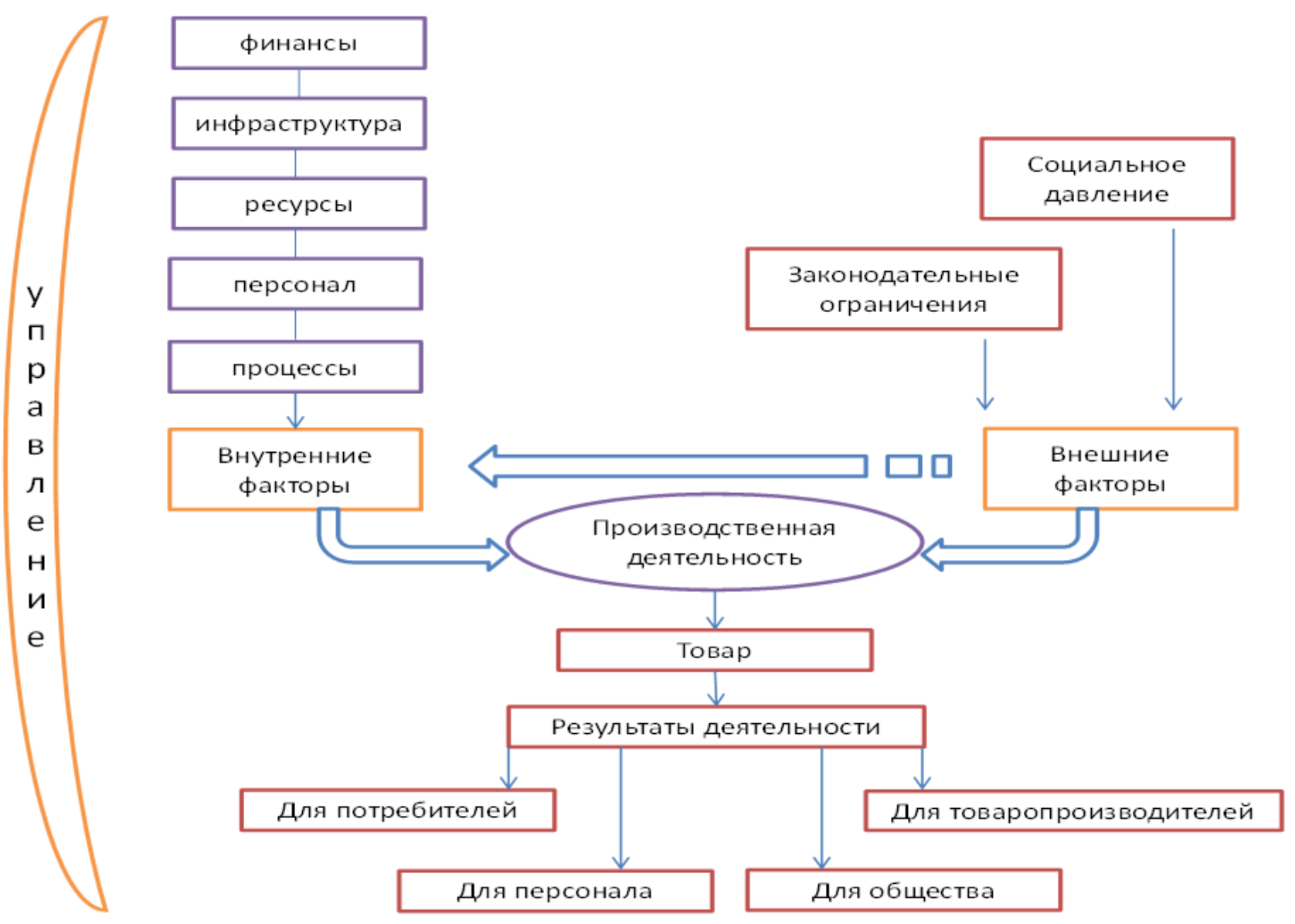

Рис. 2. Объекты управления в производственной деятельности

Не секрет, что товары для повседневной жизни были самыми первыми объектами, качеством которых люди стали управлять. К этим товарам относятся одежда, продукты питания, ткани, предметы обихода, дома, дороги и т. д. Оценивалось и контролировалось мастерство работников. И в дальнейшем, чем больше использовалось машин, инструментов, приборов для производства продукции, тем больше также приходилось управлять их качеством. Все это привело к тому, что к концу двадцатого века объектом управление стало качество самого управления.

Но, несмотря на все, качество товара, по-прежнему, остается главным объектом управления, поскольку он является объектом договорных отношений, который имеет потребителя.

Управлять производственной деятельности, качеством, внутренними факторами, воздействовать на их состояние невозможно нажимая на клавишу компьютера или педаль автомобиля. Здесь необходимы организация, планирование, 
анализ действий и контроль людей, которые выполняют процессы, влияют на них.

Помимо основного персонала организации, изготавливающего продукцию или оказывающего услугу, в производственном процессе принимают участия смежный персонал и организации, такие как: поставщики (поставляют расходуемые ресурсы); подрядчики (оказывают услуги и выполняют работы по поддержанию производственной инфраструктуры в надлежащем состоянии, участвуют в разработке и изготовлении продукции); дистрибьюторы (передача продукции потребителям). Деятельность смежного персонала также определяет фактический уровень качества продукции, работ, услуг, поэтому для менеджера организации наряду с собственным персоналом, действия менеджеров смежных организаций также является объектом управления.

Вместе с тем, управление поведением и действием потребителей, влияние на них с целью обеспечения высокого спроса и высокой прибыли - все более необходимый процесс.

Помимо всех вышеуказанных организаций имеются еще и заинтересованные стороны, оказывающие влияние на результат, при чем достаточно серьезный. К таким заинтересованным сторонам относятся: надзорные органы, общественные организации, законодатели, страховщики, владельцы, акционеры, инвесторы, кредиторы.

Управлять действиями заинтересованных сторон в полной мере не возможно, но влиять на них менеджеры организации товаропроизводителя могут. Именно поэтому они должны планировать, контролировать, организовывать и анализировать свои ответные действия.

Субъектами управления в производственной деятельности являются руководители разного уровня, такие как президент компании, директор, начальник и др. Для того, чтобы оказывать влияние на действия персонала смежных организаций и собственного персонала, они отдают распоряжения и приказы. Субъекты управления выполняют обычные управленческие функции: планирование, организация, контроль, анализ и оценка действий персонала. Помимо названных, 
субъектами управления также являются специалисты, которые не занимают руководящих должностей, но предлагающие руководству принять решение по отдельным объектам управления, например менеджер по охране труда, управлению персоналом и т. д. Но все-таки, важную и определяющую роль в управлении, естественно играет руководитель организации. Он наделен всей полнотой власти и принимает ключевые решения. Любую систему управления он приспосабливает, подгоняет под себя, с учетом своего опыта и компетенции. Поскольку все люди разные, соответственно и параметры у каждого руководителя разные. Кто-то сосредотачивает все в своих руках, кто-то же, как можно больше ответственности и полномочий передает своим заместителям. Кто-то концентрирует внимание на управлении финансами, в соответствии со своим образованием, а кто-то - на управлении производствам, по тем же причинам.

Итак, для того, чтобы та или иная спроектированная и документированная система качества, включающая управление процессами, заработала, можно использовать следующие пути решения:

а) использовать средства мотивации для персонала;

б) обучать его как по профессиональным вопросам, ток и по вопросам менеджмента качества;

в) выстроить правильные отношения с потребителями;

г) научиться так управлять поставщиками, чтобы вовремя получать от них необходимую продукцию заранее установленного качества Всеобщий менеджмент качества [2, с. 248].

Обобщая все вышесказанное, можно прийти к выводу, что действия людей, участвующих в производственной деятельности товаропроизводителя, являющимися потребителями и оказывающими существенное влияние на качество, это и есть первичный объект управления, в том числе и качеством.

\section{Сиисок литературы}

1. ГОСТ Р ИСО 9000-2008 Системы менеджмента качества. Основные положения и словарь - М.: Стандартинформ, 2009. 
2. Пономарев С.В. Управление качеством продукции. Инструменты и методы менеджмента качества / С.В. Пономарев, С.В. Мищенко - М.: Стандарты и качество, 2005. - 248 с.

3. Степанова С.А. Всеобщий менеджмент качества: Учебное пособие - М.: Стандарты и качество, 2005. - 248 с.

4. Тавер Е.И. Качество как объект управления // Методы менеджмента качества. - 2012. - №11. - С. 22-27.

\section{References}

1. GOST R ISO 9000-2008 Sistemy menedzhmenta kachestva. Osnovnye polozheniia i slovar'. (2009). Moscow: Standartinform.

2. Ponomarev, S.V., \& Mishchenko, S.V. (2005). Upravlenie kachestvom produktsii. Instrumenty i metody menedzhmenta kachestva. Moscow: Standarty i kachestvo, 248.

3. Stepanova, S.A. (2005). Vseobshchii menedzhment kachestva: Uchebnoe posobie. Moscow: Standarty i kachestvo, 248.

4. Taver, E.I. (2012). Kachestvo kak obekt upravleniia. Metody menedzhmenta kachestva, 11, 22-27.

Харитонова Екатерина Алексеевна - магистрант кафедры делового администрирования Института экономики и управления ФГБОУ ВО «Новгородский государственный университет им. Я. Мудрого», Россия, Великий Новгород.

Kharitonova Ekaterina Alexeevna - graduate student of the Department of Business Administration at the Institute of Economy and Management of FSBEI HE "Yaroslav - the - Wise Novgorod State University", Russia, Veliky Novgorod. 